\title{
Practice Characteristics of Board-certified Pediatric Anesthesiologists in the US: A Nationwide Survey
}

\author{
Matthew Muffly ${ }^{1}$, David Scheinker ${ }^{2}$, Tyler Muffly ${ }^{3}$, Mark Singleton ${ }^{1}$, Rita Agarwal ${ }^{1}$, Anita Honkanen ${ }^{1}$ \\ 1. Anesthesiology, Stanford University, Stanford, USA 2. Department of Management Science and Engineering, \\ Stanford University, Stanford, USA 3. Department of Obstetrics and Gynecology, Denver Health Hospital Authority, \\ Denver, USA
}

Corresponding author: Matthew Muffly, mmuffly@stanford.edu

\section{Abstract}

\section{Introduction}

We conducted a survey to describe the practice characteristics of anesthesiologists who have passed the American Board of Anesthesiology (ABA) Pediatric Anesthesiology Certification Examination.

\section{Methods}

In July 2017, a list of anesthesiologists who had taken the ABA Pediatric Anesthesiology Certification Examination (hereafter referred to as "pediatric anesthesiologists") was obtained from the American Board of Anesthesiologists (theaba.org). Email contact information for these individuals was collected from departmental rosters, email distribution lists, hospital or anesthesia group profiles, manuscript author contact information, website source code, and other publicly available online sources. The survey was designed using Qualtrics (Qualtrics, Provo, Utah; Seattle, Washington), a web-based tool, to ascertain residency/fellowship training history and current practice characteristics that includes: years in practice, clinical work hours per week, primary hospital setting, practice type, supervision model, estimated percentage of cases by patient age group, and percentage of respondents who cared for any patient undergoing a fellowship-level index cases within the previous year. The invitation to complete the survey included a financial incentive - the chance to win one of twenty $\$ 50$ Amazon gift cards.

\section{Results}

There were 3,492 anesthesiologists who had taken the Pediatric Anesthesiology Certification Examination since 2013. Surveys were sent to those whom an email address was identified $(2,681)$ and 962 complete survey responses were received $(35.9 \%, 962 / 2,681)$. Over $80 \%$ (785) of respondents completed a pediatric anesthesiology fellowship. Of these, 485 respondents (50.4\%) work in academic practice, 212 (22.0\%) in private practice, $233(24.2 \%)$ in private practice and have academic affiliations, and $32(3.3 \%)$ as locum tenens or in other practice settings. The majority of respondents (64.3\%) in academic practice work in freestanding children's hospitals. Pediatric anesthesiologists in academic practice and private practice with

Received 08/30/2019

Review began 09/06/2019 Review ended 09/12/2019 Published 09/24/2019

() Copyright 2019

Muffly et al. This is an open access article distributed under the terms of the Creative Commons Attribution License CC-BY 3.0., which permits unrestricted use, distribution, and reproduction in any medium, provided the original author and source are credited. academic affiliations reported caring for a greater number of younger children and doing a wider variety of index cases than respondents in private practice.

\section{Conclusion}

The extent to which pediatric anesthesiologists care for pediatric patients - particularly young children and those undergoing complex cases - varies. The variability in practice characteristics is likely a result of differences in hospital type, anesthesia practice type, geographic location, and other factors.

Categories: Anesthesiology, Pediatrics, Pediatric Surgery

Keywords: anesthesiology, pediatrics, clinical practice patterns, surveys and questionnaires

\section{Introduction}

The field of pediatric anesthesiology has evolved and grown substantially since it became an American College for Graduate Medical Education (ACGME) approved fellowship in 1997 [1]. In 2011, the pediatric anesthesia fellowship entered the National Residency Matching Program (NRMP); the American Board of Anesthesiology (ABA) began offering the Pediatric Anesthesiology Certification Examination in 2013.

Until recently, no comprehensive list of pediatric anesthesiologists in the United States (US) existed. In 2015, our group created the first database of pediatric anesthesiologist demographic characteristics and geographic locations in the US [2]. Despite the improved understanding of pediatric anesthesiologist geographic location and demographics, the practice characteristics of pediatric anesthesiologists in the US remain largely unknown. 
Understanding practice characteristics of pediatric anesthesiologists - the anesthesia practice types and hospital settings in which they work, categories of patients they care for, and for what types of procedures are necessary for a better understanding of the spectrum of anesthesia care provided to pediatric patients in the US and is relevant for workforce planning, fellowship education, and outcome research. Therefore, we conducted a survey of the practice characteristics of anesthesiologists who passed the ABA Pediatric Anesthesiology Certification Examination.

\section{Materials And Methods}

In July 2017, a list of anesthesiologists who registered for the ABA Pediatric Anesthesiology Certification Examination was obtained at "theaba.org" using the "Advanced Search" function. From October to December 2017, email contact information for these individuals was collected from departmental rosters, email distribution lists, hospital or anesthesia group profiles, manuscript author contact information, website source code, and other publicly available online sources.

The Stanford University Administrative Panel on Human Subjects in Medical Research waived the requirement for written informed consent and approved the study.

\section{Survey design}

The survey instrument was designed and distributed using Qualtrics (Qualtrics, Provo, Utah; Seattle, Washington), a web-based tool for creating and conducting online surveys. Survey questions were designed to determine residency/fellowship training history and current practice characteristics including years in practice, clinical work hours per week, primary hospital setting, practice type, supervision model, estimated percentage of cases by patient age group, and percentage of respondents who cared for any patient undergoing a fellowship-level index cases within the previous year. Fellowship-level index cases are an indicator of complex pediatric anesthesia care and include airway surgery (excluding tonsillectomy and adenoidectomy), cardiac surgery with cardiopulmonary bypass, cardiac surgery without cardiopulmonary bypass, craniofacial surgery, intra-abdominal/intracavitary surgery, intracranial neurosurgery, intrathoracic non-cardiac surgery, major orthopaedic surgery, neonatal emergency surgery, and solid organ transplant [3].

Anesthesiologist sex was imported from an existing database. The years in practice was estimated based on the time of primary board certification in anesthesia until the survey date. Survey responses were retained for those who fully completed the demographics and practice characteristics sections of the survey. Respondents and non-respondents who registered for the ABA Pediatric Anesthesiology Certification Examination but did not subsequently pass were excluded from the analysis as to include only anesthesiologists with ABA Pediatric Anesthesiology Certification.

The survey was first distributed to 20 members of the authors' department and revised based on their suggestions for clarity and for improvement. In January 2018, the revised survey was emailed to all pediatric anesthesiologists whose email address had been identified (Supplement 1). The invitation to complete the survey included a financial incentive - the chance to win one of twenty $\$ 50$ Amazon gift cards.

Two reminders were sent to survey non-respondents within the next 30 days. The survey was closed six weeks after the initial email.

\section{Results}

There were 3,492 anesthesiologists who had taken or were registered for the ABA Pediatric Anesthesiology Certification Examination in July, 2017. Surveys were sent to 2,681 individuals whose emails were identified; 962 (35.9\% of those emailed) complete survey responses were received (Figure 1). 


\section{Cureus}

Anesthesiologists registered for the ABA Pediatric Anesthesiology

Certification Examination: 3,492

Valid email identified: 2,715

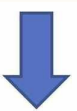

Excluded those who were subsequently found to not be board certified (34): 2,681

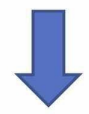

Incomplete surveys counted as non-respondents: 40

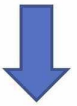

Completed surveys: 962

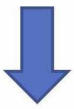

Response rate $962 / 2,681=35 \%$

FIGURE 1: Flow Diagram of Study Participants

Years in practice, sex, geographic location, and training characteristics are reported in Table 1 . Over $80 \%$ (785) of respondents completed a pediatric anesthesiology fellowship. Sixty-nine respondents (7\%) reported completing an advanced second-year fellowship, mostly in pediatric cardiac anesthesia.

\begin{tabular}{|c|c|c|}
\hline & Respondents & Non-Respondents \\
\hline & $962(35.9)$ & 1719 (64.1) \\
\hline Years in practice, median (IQR) & $10(5-20)$ & $9(5-18)$ \\
\hline \multicolumn{3}{|l|}{ Sex } \\
\hline Female & $446(46.4)$ & $781(45.4)$ \\
\hline Male & $516(53.6)$ & 938 (54.6) \\
\hline \multicolumn{3}{|l|}{ US Census Division (States) } \\
\hline East North Central (IL, IN, MI, OH, WI) & $15115.7)$ & $289(16.8)$ \\
\hline East South Central (AL, KY, MS, TN) & $30(3.1)$ & $62(3.6)$ \\
\hline Middle Atlantic (NJ, NY, PA) & $146(15.2)$ & $276(16.1)$ \\
\hline Mountain (AZ, CO, ID, MT, NM, NV, UT, WY) & $60(6.2)$ & $114(6.6)$ \\
\hline New England (CT, MA, ME, NH, RI, VT) & 74 (7.7) & $113(6.6)$ \\
\hline Pacific (AK, CA, HI, OR, WA) & $171(17.8)$ & $254(14.8)$ \\
\hline South Atlantic (DE, DC, FL, GA, MD, NC, SC, VA, WV) & $163(16.9)$ & $283(16.5)$ \\
\hline West North Central (IA, KS, MN, MO, ND, NE, SD) & $65(6.8)$ & $115(6.7)$ \\
\hline West South Central (AR, LA, OK, TX) & $100(10.4)$ & $212(12.3)$ \\
\hline
\end{tabular}




\section{Cureus}

Puerto Rico

$2(0.2)$

$1(0.1)$

Completed additional residency

No

804 (83.6)

Yes

158 (16.4)

Pediatrics

$140(88.6)$

Internal medicine

$10(6.3)$

Family medicine

Surgery

OB/Gyn

Emergency

$1(0.6)$

Completed pediatric anesthesiology fellowship

No

Yes

Completed advanced second-year fellowship

No

$716(74.4)$

Yes

Cardiac

$36(52.2)$

Research

$10(14.5)$

Pain

$6(8.7)$

Regional

QI/Patient safety

Education

Other

177 (18.4)

Did not specify

485 (50.4)

Academic

212 (22.0)

233 (24.2)

Private practice with academic affiliation

32 (3.3)

Locum tenens/other

\section{TABLE 1: Demographic and Practice Characteristics of Respondents and Non-respondents}

Of the 962 respondents, 485 (50.4\%) work in an academic practice, 212 (22.0\%) in private practice, 233 $(24.2 \%)$ in private practice and have academic affiliations, and $32(3.3 \%)$ as locum tenens or in some other practice setting.

Pediatric anesthesiologists in academic practice reported working fewer clinical hours than those in private practice or in a private practice with an academic affiliation. The majority of pediatric anesthesiologists (64\%) in academic practice work in a freestanding children's hospital at least 50\% of the time, whereas only $17 \%$ of those in private practice, and $47 \%$ of those in private practice with an academic affiliation do the same. The majority of anesthesiologists in academic practice supervise residents (96.7\%), fellows (80.8\%), certified registered nurse anesthetists (CRNAs; 86.6\%), and non-anesthesia trainees (58.6\%) whereas the majority in private practice supervise CRNAs only (Table 2). More than $20 \%$ of anesthesiologists in academic practice supervise certified anesthesiology assistants. 


\section{Cureus}

\begin{tabular}{|c|c|c|c|c|c|}
\hline & $\begin{array}{l}\text { Overall } \\
\text { ( } n=962)\end{array}$ & $\begin{array}{l}\text { Academic } \\
\text { Practice } \\
(\mathrm{n}=485)\end{array}$ & $\begin{array}{l}\text { Private } \\
\text { Practice } \\
(n=212)\end{array}$ & $\begin{array}{l}\text { Private Practice and an } \\
\text { Academic Affiliation ( } n=233 \text { ) }\end{array}$ & $\begin{array}{l}\text { Locum } \\
\text { Tenens/Other } \\
\text { ( } n=32)\end{array}$ \\
\hline Years in practice, median (IQR) & & $10(5-20)$ & $8(4-19)$ & $11(5-21)$ & $\begin{array}{l}12.5(5.75- \\
19.25)\end{array}$ \\
\hline \multicolumn{6}{|l|}{ Sex, n (\%) } \\
\hline Female & $\begin{array}{l}446 \\
(46.4)\end{array}$ & $255(52.6)$ & $95(44.8)$ & $80(34.3)$ & $16(50.0)$ \\
\hline Male & $\begin{array}{l}516 \\
(53.6)\end{array}$ & $230(47.4)$ & $117(55.2)$ & $153(65.6)$ & $16(50.0)$ \\
\hline $\begin{array}{l}\text { Clinical work hours per week, } \\
\text { mean (SD) }\end{array}$ & $\begin{array}{l}46.9 \\
(12.4)\end{array}$ & $44.9(12.6)$ & $48.5(11.6)$ & $50.3(10.8)$ & $42.4(17.3)$ \\
\hline \multicolumn{6}{|c|}{$\begin{array}{l}\text { Clinical work hours per week by sex, mean } \\
\text { (SD) }\end{array}$} \\
\hline Female & $\begin{array}{l}45.0 \\
(12.0)\end{array}$ & $44.0(12.3)$ & $46.2(11.9)$ & $47.4(10.9)$ & 43.4 (10.2) \\
\hline Male & $\begin{array}{l}48.5 \\
(12.5)\end{array}$ & $45.8(12.9)$ & $50.4(11.0)$ & $51.8(10.4)$ & $41.4(22.0)$ \\
\hline \multicolumn{6}{|c|}{$\begin{array}{l}\text { Hospital setting (at least } 50 \% \text { of time), } n \\
(\%)^{\wedge}\end{array}$} \\
\hline $\begin{array}{l}\text { General hospital WITHOUT } \\
\text { dedicated children's unit }\end{array}$ & $99(10.3)$ & $27(5.6)$ & $46(21.7)$ & $19(8.2)$ & $7(21.9)$ \\
\hline $\begin{array}{l}\text { General hospital WITH } \\
\text { dedicated children's unit }\end{array}$ & $\begin{array}{l}343 \\
(35.7)\end{array}$ & $144(29.7)$ & 98 (46.2) & $91(39.1)$ & $10(31.3)$ \\
\hline $\begin{array}{l}\text { Freestanding children's } \\
\text { hospital }\end{array}$ & $\begin{array}{l}470 \\
(48.9)\end{array}$ & $312(64.3)$ & $36(17.0)$ & 110 (47.2) & $12(37.5)$ \\
\hline Ambulatory surgery center & $52(5.4)$ & $9(1.9)$ & $32(15.1)$ & $9(3.9)$ & $2(6.3)$ \\
\hline $\begin{array}{l}\text { Other (VA, office-based, } \\
\text { dental setting) }\end{array}$ & $9(0.9)$ & $2(0.4)$ & $4(1.9)$ & $0(0)$ & $3(9.4)$ \\
\hline \multicolumn{6}{|l|}{$\begin{array}{l}\text { Respondents who supervise, } n \\
\text { (\%) }\end{array}$} \\
\hline Residents & $\begin{array}{l}648 \\
(67.4)\end{array}$ & $469(96.7)$ & $19(9.0)$ & $152(65.2)$ & $8(25.0)$ \\
\hline Fellows & $\begin{array}{l}455 \\
(47.3)\end{array}$ & $392(80.8)$ & $5(2.4)$ & $57(24.5)$ & $1(3.1)$ \\
\hline $\begin{array}{l}\text { Certified registered nurse } \\
\text { anesthetists }\end{array}$ & $\begin{array}{l}735 \\
(76.4)\end{array}$ & $420(86.6)$ & $125(59.0)$ & $174(74.7)$ & $16(50.0)$ \\
\hline $\begin{array}{l}\text { Certified anesthesiology } \\
\text { assistants }\end{array}$ & $\begin{array}{l}160 \\
(16.6)\end{array}$ & $106(21.9)$ & $18(8.5)$ & 31 (13.3) & $5(15.6)$ \\
\hline Non-anesthesia trainees & $\begin{array}{l}434 \\
(45.1)\end{array}$ & $284(58.6)$ & 45 (21.2) & $100(42.9)$ & $5(15.6)$ \\
\hline \multicolumn{6}{|c|}{ Mean percentage of time by practice setting } \\
\hline Operating room & 92.7 & 90.7 & 95.5 & 95.1 & 87.5 \\
\hline Acute pain service & 3.3 & 3.9 & 2.5 & 2.8 & 2 \\
\hline Chronic pain service & 1.2 & 2.2 & 0.2 & 0.4 & 0 \\
\hline Pediatric intensive care & 1.6 & 2.3 & 0.6 & 1 & 0.8 \\
\hline Other & 1.2 & 0.9 & 1.1 & 0.7 & 9.7 \\
\hline
\end{tabular}




\section{Cureus}

Percentage of cases by age

Infants/children (aged 0-2 years)

Children (aged three years to five years)

Older children (aged six years to 17 years)

Adults (aged 18+ years)
21

25.3

14.6

20.7

20.2

$\begin{array}{llll}24.7 & 27.4 & 18.6 & 24.6\end{array}$

$16.9 \quad 25.4$

29.3
25.4

31.2

Number of anesthesiologists who cared for patients undergoing index cases within the past 12 months, $n(\%)$

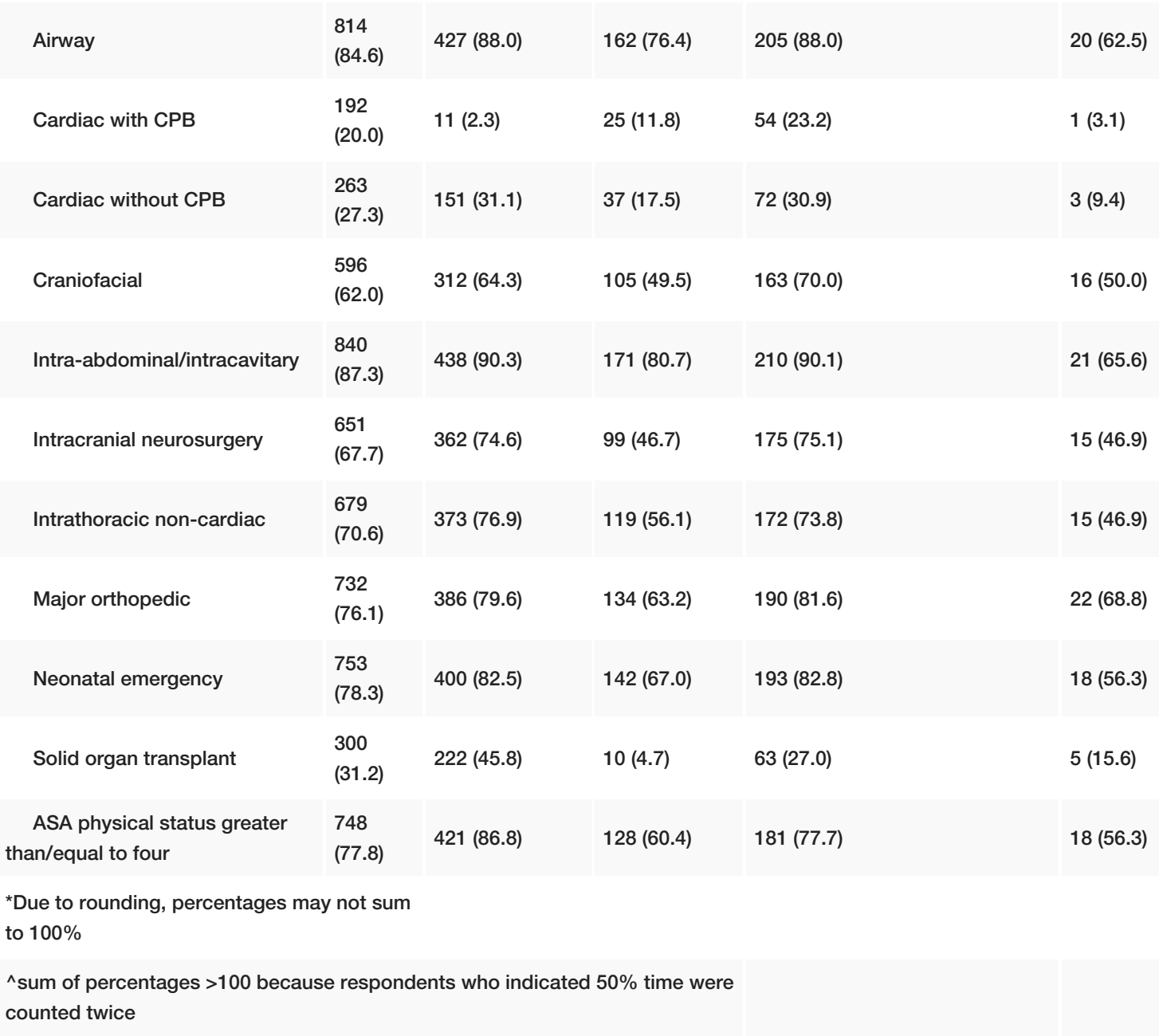

TABLE 2: Practice Characteristics by Practice Type

Pediatric anesthesiologists in academic practice indicated that the majority of their patients were five years old or younger (52.7\%) versus $33.2 \%$ for those in private practice, and $45.3 \%$ for those in private practice with an academic affiliation. All practice characteristics, stratified by anesthesia practice type, are shown in Table 2 .

\section{Discussion}

The results of this survey illustrate the practice characteristics of anesthesiologists who successfully completed the ABA Pediatric Anesthesia Certification. An understanding of their practice characteristics is important for workforce planning, fellowship education, outcome research, and optimizing the care of children.

The results of this survey suggest that, in general, respondents in academic practice or private practice with academic affiliations care for a higher percentage of younger patients as well for as patients undergoing a 
wider variety of fellow-level index cases, than those in private practice. Over $90 \%$ of all respondents, regardless of practice type, reported caring for patients undergoing at least one index-level case type in the past year. On the other hand, nearly one in 10 respondents in private practice (or one in 20 respondents in academic practice or academic practice with an academic affiliation) reported caring for no patients undergoing an index case within the preceding year.

This issue is particularly timely, given the potential effect of the American College of Surgeon's Children's Surgery Verification Quality Improvement Program on the distribution of pediatric surgery in the US. It is possible that with regionalization of pediatric surgical procedures, the number of pediatric cases per pediatric anesthesiologist at non-tertiary care children's hospitals will decrease. This raises questions about how anesthesiologists will maintain clinical competency given a potential reduction in the number of children undergoing care in the community hospital setting.

There are certain limitations that should be considered when interpreting the results of this survey. The survey describes the practice characteristics of anesthesiologists who passed the ABA Pediatric Anesthesiology Certification Examination; the respondents may be biased toward the academic end of the practice spectrum, where certification is often required. In addition, there are many anesthesiologists who did not take the ABA Pediatric Anesthesiology Certification Examination who nevertheless care for children routinely. Anesthesiologists who trained before the advent of time-limited anesthesiology subspecialty boards hold board certifications that include all subspecialties. The survey misses a large number of legitimately qualified practitioners who hold "board certified" status in the field of anesthesiology inclusive of pediatric anesthesiology. In addition, the survey response rate was low (35.9\%), thus raising the possibility of bias in the results. Although respondents and non-respondents appeared similar in terms of sex, years in practice, and geographic location, they may differ in unobservable ways, thus potentially limiting the generalizability of the results. Nevertheless, this survey gives us an improved understanding of the practice characteristics of those pediatric anesthesiologists with ABA Pediatric Anesthesiology Certification.

\section{Conclusions}

The practice characteristics of pediatric anesthesiologists are now better understood. The extent to which pediatric anesthesiologists care for pediatric patients - particularly young children and those undergoing complex cases - varies. The variability in practice characteristics is likely a result of differences in hospital type, anesthesia practice type, geographic location, and other factors.

\section{Appendices}

Practice Characteristics of Board-Certified Pediatric Anesthesiologists

Do you agree to proceed?

o Yes (1)

o No (2)

The first set of questions is about your TRAINING.

1. Did you complete a residency IN ADDITION to Anesthesiology?

o Yes (1)

o No (2)

Which additional residency did you complete?

2. Did you complete a Pediatric Anesthesiology Fellowship? 


\section{Cureus}

o Yes (1)

o No (2)

3. When did you complete your Pediatric Anesthesiology Fellowship?

$\boldsymbol{\nabla} 2017$ (1) ... 1967 (51)

4. After Pediatric Anesthesiology Fellowship, did you complete an Advanced Second Year Fellowship in Pediatric Anesthesiology?

o Yes (1)

o No (2)

What was your Advanced Second Year Fellowship in Pediatric Anesthesiology (select all that apply)?

$\square \quad$ Cardiac (1)

$\square \quad$ Pain (2)

$\square \quad$ Regional (3)

$\square \quad$ Research (4)

$\square \quad$ Quality Improvement/Patient Safety (5)

$\square \quad$ Education (8)

$\square \quad$ Other (6)

5. Which of the following best describes your current anesthesiology practice?

o Academic Practice (3)

o Private Practice (1)

o Private Practice with Academic Affiliation (2)

o Locum Tenens (5)

o Other, please describe: (4)

6. Please indicate if you currently supervise any of the following (select all that apply):

$\square \quad$ Anesthesiology Residents (1)

$\square \quad$ Anesthesiology Fellows (2)

$\square \quad$ Certified Registered Nurse Anesthetists (CRNA) (3) 


\section{Cureus}

$\square \quad$ Anesthesia Assistants (AA) (6)

$\square \quad$ Non-anesthesia Trainees (4)

7. What percentage of time do you care for patients in the following settings? (must total 100\%)

General Adult Hospital WITHOUT dedicated areas for care of children :

General Adult Hospital WITH dedicated areas for care of children :

(2)

Freestanding Children's Hospital :

Ambulatory Surgery Center :

Veteran's Administration :

(6)

Office-Based Practice :

(5)

Dental Practice :

(7)

Other : (8)

Total :

8. On average, how many hours per week do you spend directly caring for patients?

9. What is the ZIP code of your main employment site?

10. What percentage of time do you care for patients in each of the following services/settings? (must total $100 \%)$

Operating Room and Out-of-Operating Room Anesthetizing Locations :

Acute Pain/Regional Service :

Chronic Pain Service :

Pediatric Intensive Care Unit :

Other :

Total :

11. Estimate the percentage of patients in each age cohort you care for in your practice (must total $100 \%$ )

Age 0 - 2 Years :

Age 3 - 5 Years : 


\section{Cureus}

Age 6 - 17 Years :

Age 18+ Years

Total :

12. Indicate the types of pediatric cases (age 0-17 years) that you have done in the past 12 months (select all that apply)

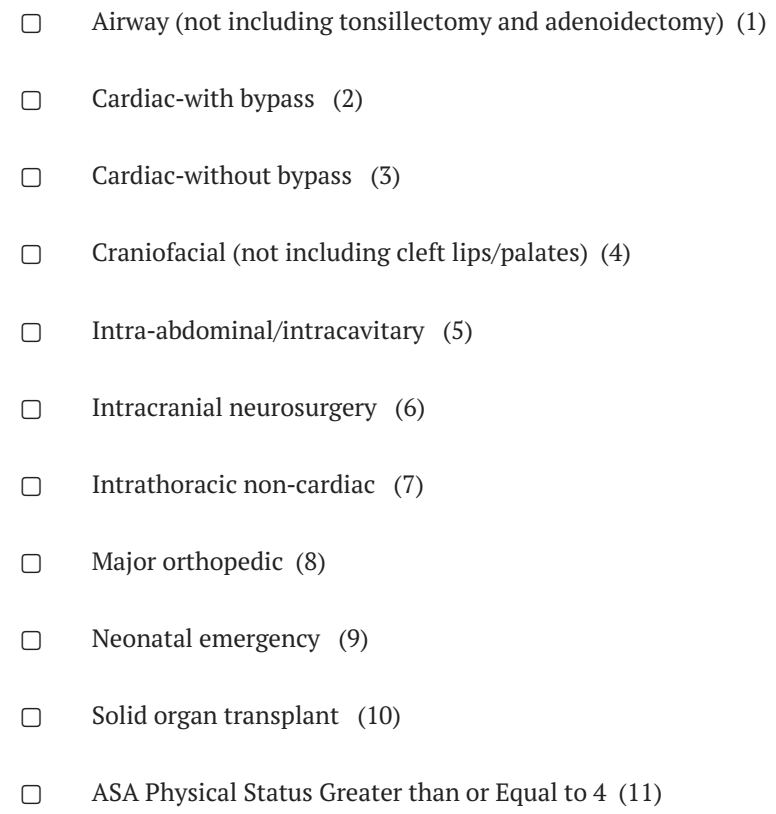

13. How satisfied are you with your current practice?

Likert Scale: Very Dissatisfied (0) - Very Satisfied (10)

Reasons for degree of satisfaction (optional):

14. Is there a need for additional pediatric anesthesiologists in your geographic area?

o Yes

No

o Not Sure

15. Is there any additional information you would like to add about the job market in your area (optional)?

Thank you, you are done! 


\section{Cureus}

o Yes (1)

o No (2)

Name:

Email:

\section{Additional Information}

\section{Disclosures}

Human subjects: Consent was obtained by all participants in this study. Stanford Committee for the Protection of Human Subjects issued approval 42485. The Stanford Committee for the Protection of Human Subjects waived the requirement for informed consent for this survey study. Animal subjects: All authors have confirmed that this study did not involve animal subjects or tissue. Conflicts of interest: In compliance with the ICMJE uniform disclosure form, all authors declare the following: Payment/services info: All authors have declared that no financial support was received from any organization for the submitted work. Financial relationships: All authors have declared that they have no financial relationships at present or within the previous three years with any organizations that might have an interest in the submitted work. Other relationships: All authors have declared that there are no other relationships or activities that could appear to have influenced the submitted work.

\section{References}

1. Rockoff MA, Hall SC: Subspecialty training in pediatric anesthesiology: what does it mean? . Anesth Analg. 1997, 85:1185-90. 10.1097/00000539-199712000-00001

2. Muffly MK, Muffly TM, Weterings R, Singleton M, Honkanen A: The current landscape of US pediatric anesthesiologists: demographic characteristics and geographic distribution. Anesth Analg. 2016, 123:17985. 10.1213/ANE.0000000000001266

3. Accreditation Council for Graduate Medical Education (ACGME) website . (2019). Accessed: September 21, 2019: https://www.acgme.org/Portals/0/PFAssets/ProgramResources/042_Peds_AN_Minimums.pdf. 